\title{
Gender differences in recognising depression in a case vignette in a university student population: Interaction of participant and vignette subject gender with depressive symptomatology*
}

\author{
Junko Andou", Toshinori Kitamura, ${ }^{2,3 \#}$ \\ ${ }^{1}$ Asahi Clinic, Kawagoe, Japan \\ ${ }^{2}$ Kitamura Institute of Mental Health Tokyo, Tokyo, Japan \\ ${ }^{3}$ Department of Psychiatry, Graduate School of Medicine, Nagoya University, Nagoya, Japan \\ Email: "kitamura@,institute-of-mental-health.jp
}

Received 31 August 2013; revised 28 September 2013; accepted 6 October 2013

Copyright (C) 2013 Junko Andou, Toshinori Kitamura. This is an open access article distributed under the Creative Commons Attribution License, which permits unrestricted use, distribution, and reproduction in any medium, provided the original work is properly cited.

\begin{abstract}
Objective: Gender difference in depression prevalence may be explained by variation in the recognition of depression due to differences in gender identity. Method: We distributed one of four questionnaires describing fictional cases of Major Depressive Episode (MDE) (2 predominant symptom types $\times 2$ case vignette subject genders) to 72 students. Participants were asked whether and how much they thought the subject in the case was emotionally as well as somatically ill. They were also administered the Center for Epidemiologic Studies-Depression Scale and the Ito Sex Role Scale. Results: Participants scoring high in gender identity communion and ideal gender roles communion and delicacy were more likely to identify the vignette subject as ill. The severity of somatic illness was rated more highly for the case of predominantly somatic symptomatology. The recognition of severity of psychological illness was influenced by two interactive terms: the gender of the vignette subjects $x$ gender of the participants and predominant symptoms $x$ gender of the vignette subjects. Recognition of MDE case vignettes as indicating illness, particularly psychological illness, was more likely when the participant was female, scored highly in femininity, or was of the gender as the case subject. Conclusion: These findings may be concordant with the self-schema theory.
\end{abstract}

*Conflict of interest: None.

${ }^{\#}$ Corresponding author.
Keywords: Depression; Gender Difference; Gender Identity; Gender Role

\section{INTRODUCTION}

Epidemiological research has consistently shown that the prevalence of depression is approximately twice as high among women as among men [1-10]. There are, however, puzzling observations. First, gender differences have been noted only from the mid- $20 \mathrm{~s}$ to around 60 years of age [1-14]. Second, the prevalence of depression is very similar between men and women when examining individuals belonging to socially homogeneous groups [15]. The explanations for these findings include biological, psychological, and sociological factors [2,16,17]. Possible psychological and social explanations are that women are more likely to 1) encounter negative life events [18$20]$; 2) have had more negative "depressogenic" experiences during childhood [21];3) be required to take on more social roles [4,22]; 4) adjust with life adversities by using specific coping styles [23]; 5) have poorer social support [24]; or 6) recognize their situations in a maladjusted way [25-27]. However, no consensus on these various theories has been achieved thus far.

In the present study, we adopted the self-schema theory in explaining gender differences in depression prevalence. Psychiatric symptoms may be internally experienced through a variety of "filters" until they are recognized and reported as a mental illness. First, symptoms must be recognized as demonstrating ill health. If symptoms are recognized as a part of normal (physio- 
logical) experience, individuals are less likely to report them as symptoms. At this stage, the distinction is between "normal" and "abnormal" (ill-ness). At the second stage, after symptoms are recognized as indicating illness, individuals view them as either somatic, psychological, or both. If they attribute symptoms to purely somatic domains, they are unlikely to report them as psychological symptoms even if asked directly. Only when they attribute symptoms to the psychological domain are they likely to respond positively to an enquiry regarding psychological illness. Therefore, it may be that not all individuals with psychiatric symptoms recognize and report them as indicators of psychological illness. If the passage through these two "filters" differs between men and women, then the frequency with which symptoms are reported as indicating mental illness will vary between these two groups even when the psychiatric symptoms are experienced with equal prevalence.

Self-schema research shows that an individual confronted with a vast amount of information only pays attention to, perceives, and selects that which fits the cognitive structure of the self. Self-schemata are "cognitive generalizations about the self $\cdots$ that organize and guide the processing of self-related information" [28]. Information that matches the self-schemata is selected and perceived more easily, and is expected to occur with more likelihood, than that which does not.

We have speculated that recognizing depressive symptoms as indicative of illness is subject to the influence of one's self-schema. If the self-schema matches one's suffering, these experiences are more easily recognized as manifestations of illness; if the self-schema does not match, symptoms are less likely to be recognized as an illness. Gender identity and gender role comprise a behavior domain in which individuals can have self-schemata [29]. Depression is prototypically regarded as a feminine trait $[30,31]$. Men may be uncomfortable identifying internal symptoms as signs of illness. If women do so, on the other hand, they are conforming to the female role that is expected of them. Gender roles may therefore influence the recognition of internal symptoms as suffering [32].

We were interested in how individuals perceived their depressive symptomatology as illness and attributed it to the psychological rather than somatic domain. However, depressive symptomatology varies from person to person as well as from time to time. Hence, we presented participants with the same fictional case of Major Depressive Episode (MDE) and asked them to judge how ill the case subject was. We speculated that people would recognize depression in others to the same extent that they would for their own condition, and that gender identity and gender role would influence the degree to which participants would judge how psychologically ill the case subject was.

A second hypothesis was that according to the selfschema theory, individuals would be more likely to recognize depressive symptoms in persons of the same gender. In psychotherapy, it is often stated that female patients prefer same-gender therapists [33,34], while female therapists form more effective therapeutic alliances with women [35], although patient and therapist gender does not affect treatment outcomes [36]. After controlling for gender identity and gender role, depression may be recognized more easily if the case subject is of the same gender as the participants.

A third speculation was that the recognition of depressive symptoms as indicative of illness would be biased by the type of symptoms: somatic or emotional. Those experiencing clinical depression would not always recognize their symptoms as those of psychological suffering. Individuals with mental disorders may believe their suffering to be somatic in nature. Bridge et al. [37] coined the terms "psychologisers" and "somatisers" to distinguish the two. At the same time, clinical depression manifests itself in a variety of ways. A meta-analysis of depression measures indicated that depression symptomatology is multifaceted, usually consisting of emotional, cognitive, and somatic elements [38]. Therefore, the predominant symptoms of depressive illness may vary from one person to another. In the present study, we were interested in subjective judgments of the illness condition as either psychological or somatic. Men may associate illness more readily with somatic rather than emotional symptoms, because this approach corresponds to their self-schemata as men.

In the current study, we presented male and female students with one of four MDE case vignettes and asked them to judge separately the severity of somatic and psychological illness. The case vignettes differed in terms of the predominant symptoms (somatic vs. emotional) and gender of the case subject (male vs. female).

Our hypotheses were as follows:

1) Male participants would recognize depressive symptoms as manifestations of illness less frequently than would female participants.

2) Participants would recognize depressive symptoms as manifestations of illness more frequently when case subjects were of the same gender (a boy for male participants and a girl for female participants) than when they were of the opposite gender.

3) Participants would recognize depressive symptoms as manifestations of illness more frequently for a male case subject with predominantly somatic symptoms than for a male case subject with predominantly emotional symptoms, and more frequently for a female case subject with predominantly emotional symptoms than a female case subject with predominantly somatic symptoms. 
4) Participants scoring high in femininity would be more likely to recognize depressive symptoms as manifestations of illness compared to participants scoring low in femininity; students scoring high in masculinity would be less likely to recognize depressive symptoms as manifestations of illness compared to participants scoring low in masculinity.

5) After recognizing symptoms as manifestations of illness, participants would be more likely to attribute the associated case to the psychological domain in instances where the case subject was male and had somatic symptoms or the case subject was female and had emotional symptoms.

6) Participants scoring high in femininity would be more likely to attribute a case to the psychological domain whereas participants scoring high in masculinity would be more likely to attribute the same symptoms to the somatic domain.

\section{METHODS}

\subsection{Participants}

A total of 154 university students attending a psychology course were invited to take part in this questionnaire survey. They represented different departments within the same university. None of them had taken courses in medicine or nursing. The questionnaire was distributed and returned during the same class session. One hundred and fifty (97\%) students replied to the questionnaires and were credited for their participation. Respondents included 70 males and 80 females, with a mean age of 18.7 $(\mathrm{SD}=0.8)$; the mean age was $18.9(\mathrm{SD}=0.9)$ for men and $18.6(\mathrm{SD}=0.7)$ for women.

The questionnaires involving the MDE and Panic Disorder cases were distributed separately, with 72 students receiving the MDE case and 78 students receiving the Panic Disorder case. Because our main interest was the recognition of depression severity, we will report here the results derived from the 72 students who evaluated the MDE case. The results of analyses on students' recognition of panic severity will be reported elsewhere.

This project was approved by the Ethical Committee of the National Center of Neurology and Psychiatry, Kohnodai Campus (Japan).

\subsection{Case Vignettes}

We used four imaginary cases of young people who recently suffered from MDE according to the Diagnostic and Statistical Manual of Mental Disorders 4th Edition [39] (Appendix). The four vignettes were characterized by the gender of the case subject (the boy was named "Hiroshi" and the girl was named "Yuuko", both being common names for boys and girls in Japan) and the predominant symptoms of the case subject (emotional or somatic). For predominantly emotional symptoms, the case subject was characterized by the recent onset of despondent mood, worthlessness, and difficulty with decision making. For predominantly somatic symptoms, the case subject demonstrated the recent onset of loss of energy, difficult sleeping, and no appetite. The total number of DSM-IV diagnostic symptoms (criterion A of MDE) was the same for the two vignettes. Symptom severities, determined according to the Global Assessment of Function (GAF) [39], were set at between 41 and 50 across the vignettes. Each participant was given one of the four vignettes.

\subsection{Measurements}

Severity judgment: Each participant was asked to judge (a) if he/she thought the male/female case subject was "somatically ill" and (b) if he/she thought the male/ female case subject was "psychologically ill". If the participant believed the case subject to be somatically or psychologically ill (or both), further enquiry was made as to the degree of severity of the somatic or psychological illness using a 4-point scale (very mild, 1; mild, 2; severe, 3 ; and very severe, 4 ). If the participant thought that the case did not demonstrate an illness of any kind, it was rated as 0 . Note that we avoided using the term "mentally" ill because of its connotation implying mental "disorder".

Participants' depression: Each participants' current depressive state was rated using the Center for Epidemiologic Studies-Depression Scale (CES-D) [40]. The CES-D is a self-report measure of depression consisting of 20 items. It was developed for use in studies on the epidemiology of depressive symptomatology in general populations. Reliability and validity has been reported [40]. The CES-D was translated into Japanese and the validity of the Japanese version was confirmed [41]. Higher scores indicate a greater severity of depression.

Gender identity and ideal gender role: The Ito Sex Role Scale (ISRS) [42] was used to assess men's and women's gender identities and ideal gender roles. We believe that gender roles are highly culture specific and therefore decided to use a scale developed for a Japanese population. Moreover, the ISRS is unique in that it considers separately the individual's image of the self in terms of sex role and the ideal roles that men and women are expected to take. The ISRS consists of 24 items, with three subscales: "Agency" is associated with masculinity, "Communion" is associated with empathy and humanity, and "Delicacy" is associated with femininity. Ito [42] did not use the terms "masculinity" and "femininity" to avoid confusion that might arise from distinctions between sex and gender. 


\subsection{Statistical Analyses}

First, we compared participants who did not believe the cases demonstrated either somatic or psychological illness with those who did, in terms of the gender of the participants (male vs. female), predominant symptoms (somatic vs. emotional), the gender of the case subject (male vs. female), and participants' gender identities and gender roles. We compared the somatic and psychological severity judgments of the male and female participants for each of the four case vignettes. We then examined whether the severity judgment for each vignette was influenced by the predominant symptoms (somatic vs. emotional), the gender of the case subject (male vs. female), the gender of the participant (male vs. female), or the current depression severity of the participants. In order to examine the interactions of these variables with the severity ratings, three-way analyses of variance (ANOVA) were performed using severity judgments as dependent variables and the predominant symptoms, the gender of the case subject, and the gender of the participant as dependent variables. We also correlated the subscales of the ISRS with the severity judgments of the male and female participants for each of the four case vignettes. Finally, we examined the correlations between severity ratings and gender identity and ideal gender role.

\section{RESULTS}

\subsection{Recognition of Case Subjects as Being Ill}

Of the 76 participants, five $(6.6 \%)$ did not believe the case subject was either somatically or psychologically ill. These five participants were all male students. The difference between male and female students barely failed to reach statistical significance (Fisher's exact probability, $P=0.054)$. The case containing predominantly somatic symptoms $(5.4 \%)$ and that containing predominantly emotional symptoms (7.7\%) did not differ in the rate at which the case subject was not recognized as being ill. The male case subject $(2.7 \%)$ was less likely to be recognized as not ill than the female case subject (10.3\%), but this difference was not significant (Fisher's exact probability $P=0.359$ ). The participants who recognized the case subjects as ill scored significantly higher in the Communion subscale of gender identity and the Communion and Delicacy subscales of ideal gender role (Table 1).

The Communion subscale of ideal gender role was significantly higher in female participants $(\mathrm{M}=34.2, \mathrm{SD}$ = 3.6) than in male participants $(\mathrm{M}=27.0, \mathrm{SD}=6.4)(\mathrm{t}$ $(36)=3.8, P<0.001)$. The Delicacy subscale of ideal gender role was also higher in female participants $(\mathrm{M}=$ $28.9, \mathrm{SD}=5.0)$ than in male participants $(\mathrm{M}=21.8, \mathrm{SD}$ $=3.9)(\mathrm{t}(36)=3.0, P<0.01)$.
Table 1. Gender identity and ideal gender role scores corresponding to interpretation of the case as indicating illness.

\begin{tabular}{|c|c|c|}
\hline & Illness $(\mathrm{n}=71)$ & Non-illness $(n=5)$ \\
\hline \multicolumn{3}{|c|}{ (Gender identity) } \\
\hline Agency & $43.8(9.0)$ & $42.2(10.7)$ \\
\hline Communion $^{*}$ & $26.7(4.2)$ & $22.8(3.3)$ \\
\hline Delicacy & $22.5(4.6)$ & $20.0(5.4)$ \\
\hline \multicolumn{3}{|c|}{ (Ideal gender role) } \\
\hline Agency & $61.9(8.7)$ & $57.2(8.9)$ \\
\hline Communion $^{* * *}$ & $35.6(4.1)$ & $27.0(6.4)$ \\
\hline Delicacy $^{* * *}$ & $30.8(5.4)$ & $21.8(3.9)$ \\
\hline
\end{tabular}

${ }^{*} P<0.05 ;{ }^{* *} \mathrm{P}<0.01 ;{ }^{* * *} \mathrm{P}<0.001$.

In order to examine the relative contribution of participant gender and the gender identity and ideal gender role items on the interpretation of the case as demonstrating illness, we performed a discriminant function analysis with the case interpretation as the criterion variable and the gender of the participant, the type of symptoms, the gender of the case subject, and the ISRI items as the independent valuables. A stepwise method for minimising Wilk's lambda was used; the best discriminator was entered stepwise until all variables with significant contribution were entered. Two variables emerged as significant contributors to case interpretation, the Communion subscale of ideal gender role (standardised discriminate function coefficient, 0.94), and the Delicacy subscale of gender identity $(0.51)$. Thus the contribution of gender identity and role exceeded that of the gender of the participant. Canonical correlation was 0.59 .

\subsection{Case Subjects Judged as IIl}

We expected that the somatic and psychological severity ratings would show a strong negative correlation. They were, however, slightly correlated $(\mathrm{r}=0.036$, $\mathrm{ns})$, and this was also the case when the male and female participants were examined separately (men: $r=0-0.004$, ns; women: $r=0.072, n s$ ). Therefore, further analyses considered separately the severity judgments of somatic and psychological illness.

The mean (SD) severity judgment of somatic illness across the four case vignettes was $0.6(0.9)$; there appeared to be no difference between the male and female participants (men: 0.6, SD 0.8; women: 0.6, SD 0.9). The mean (SD) severity judgment of psychological illness across the four case vignettes was 2.3 (0.9); again there appeared to be no difference between the male and female participants (men: $\mathrm{M}=2.5, \mathrm{SD}=0.9$; women: $\mathrm{M}=$ $2.1, \mathrm{SD}=0.8)$. However, the rating of psychological severity $(\mathrm{M}=2.3, \mathrm{SD}=0.9)$ was significantly higher than that of somatic severity $(\mathrm{M}=0.6, \mathrm{SD}=0.9)(\mathrm{t}(70)=$ $11.8, P<0.001)$. This was also true when the cases con- 
taining predominantly somatic and emotional symptoms were evaluated separately, when the vignettes with male and female case subjects were evaluated separately, and when male and female participants were evaluated separately. The mean (SD) CES-D score was 43.0 (9.5); it was 21.4 (10.8) for men and 17.9 (8.2) for women (sex difference, ns). The participants' CES-D scores were not significantly correlated with the severity judgment scores (severity of somatic illness: $r=0-0.067$, ns; severity of psychological illness: $\mathrm{r}=0-0.048, \mathrm{~ns})$.

\subsection{Effects of Predominant Symptoms, Vignette Subject Gender, and Participant Gender on Participants' Assessment of Somatic Illness Severity}

The severity rating of somatic illness was significantly higher when participants judged the somatic symptoms case $(\mathrm{M}=0.9, \mathrm{SD}=0.9)$ than when they judged the emotional symptoms case $(\mathrm{M}=0.3, \mathrm{SD}=0.7)(\mathrm{t}(69)=$ $3.54, P<0.001)$. It did not differ between male $(\mathrm{M}=0.5$, $\mathrm{SD}=0.8)$ and female case subjects $(\mathrm{M}=0.7, \mathrm{SD}=0.9)$, or between male $(\mathrm{M}=0.6, \mathrm{SD}=0.8)$ and female participants $(\mathrm{M}=0.6, \mathrm{SD}=0.9)$.

A three-way ANOVA was performed with the somatic severity judgement as the criterion variable and the predominant symptoms of the vignette (somatic vs. emotional), the gender of the vignette subjects (male vs. female), and the gender of the participants (male vs. female) as the independent variable. Statistical significance was set at $P<0.05$. Among the three independent variables, only the predominant symptom showed a significant main effect $(\mathrm{F}(1)=9.93, P<0.01)$. Cases with predominantly somatic symptoms were scored higher in severity of somatic illness than cases with predominantly emotional symptoms. No other variables showed main effects on the assessment of the severity of somatic illness. We also failed to find any significant two- or threeway interactive effects.

\subsection{Effects of the Predominant Symptoms, Vignette Subject Gender, and Participant Gender on Participants' Assessment of Psychological Illness Severity}

The severity rating of psychological illness did not differ between cases of somatic $(\mathrm{M}=2.5, \mathrm{SD}=0.8)$ and emotional symptoms $(\mathrm{M}=2.1, \mathrm{SD}=1.0)$, between male $(\mathrm{M}$ $=2.3, \mathrm{SD}=0.9)$ and female case subjects $(\mathrm{M}=2.2, \mathrm{SD}$ $0.8)$, or between male $(\mathrm{M}=2.5, \mathrm{SD}=0.9)$ and female participants $(\mathrm{M}=2.1, \mathrm{SD}=0.8)$.

We performed a three-way ANOVA with the severity of psychological illness as the criterion variable and the predominant symptoms of the vignette (somatic vs. emotional), the gender of the vignette subjects (male vs. fe- male), and the gender of the participants (male vs. female) as the independent variables. Statistical significance was set at $P<0.05$. None of the three independent variables - the predominant symptoms $(\mathrm{F}(1)=2.52$, ns); the gender of the vignette subject $(\mathrm{F}(1)=1.14$, ns); the participant gender $(\mathrm{F}(1)=0.20$, ns) - showed a main effect. However, two interaction effects were significant: the gender of the vignette subjects $\mathrm{x}$ gender of the participants $(\mathrm{F}(1)=6.10, P<0.01)$ and predominant symptoms $\mathrm{x}$ gender of the vignette subjects $(\mathrm{F}(1)=5.35, P<0.05)$. Predominant symptoms $x$ gender of the participants showed no interactive effect $(F(1)=0.07$, ns). Three-way interaction was not significant (F $(1)=0.94$, ns).

Male participants rated the severity of psychological illness more highly for male case subjects $(\mathrm{M}=2.6)$ than for female case subjects $(M=1.7)$, whereas female participants rated this severity more highly for female case subjects $(M=2.3)$ than for male case subjects $(M=1.9)$ (Figure 1). The severity of psychological illness in the male case was rated more highly when the predominant symptoms were somatic $(\mathrm{M}=2.7)$ than when they were emotional $(\mathrm{M}=1.8)$, whereas the severity of psychological illness in the female case was rated more highly when the predominant symptoms were emotional $(\mathrm{M}=$ 2.1) than when they were somatic $(M=2.0)$ (Figure 2).

\subsection{Effects of Gender Identity and Ideal Gender Role on Severity Ratings}

To reveal whether the ISRI items mediated the ratings of severity, correlations between the assessment of psychological severity or somatic severity and gender identities and ideal gender roles were tested using Spearman's correlation test. The psychological severity judgement was correlated significantly with the ideal gender role subscales of Communion $(\mathrm{r}=0.384, P<0.01)$ and Delicacy ( $r=0.291, P<0.05)$. However, when the effect of participant gender was controlled for, the significance disappeared $(r=0.265, r=0.109$, respectively).

\section{DISCUSSION}

Our first hypothesis, that male participants would be less likely than female participants to interpret a case vignette of MDE as indicating illness, was marginally supported. Only male participants interpreted case vignette subjects as non-ill, although the majority of male participants recognized case subjects as suffering from illness.

Our second hypothesis, that a cross-gender difference would exist between participants and cases, was supported for psychological severity (Figure 1) but not for somatic severity. This may be due to the low rating of somatic severity.

Our third hypothesis, that there would exist interaction between case subject gender and predominant symp- 


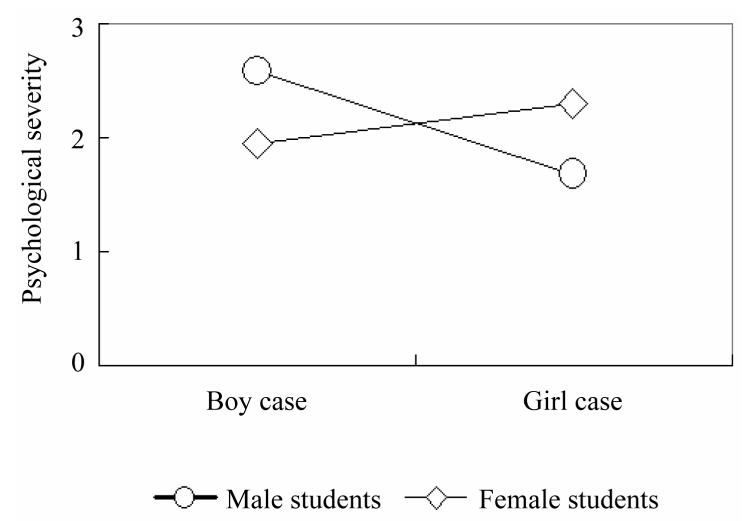

Figure 1. The psychological severity ratings for the male and female cases as rated by male and female participants.

tomatology, was supported (Figure 2). Again, this was the case only for psychological severity.

Fourthly, we expected that the interpretation of the MDE case as indicating illness would be related to femininity. The results showed that participants who recognized case vignette subjects as ill scored higher in the gender role subscale of Delicacy (femininity). They also scored higher in the Communion subscale of gender identity and ideal gender role, i.e., empathy unrelated to gender. A discriminant function analysis revealed that the Communion subscale of ideal gender role and the Delicacy subscale of gender identity contributed significantly to the recognition of vignettes as cases of illness, but the gender of the participant did not.

These findings suggest that recognition of MDE as an illness (regardless of its somatic or psychological symptomatology) is more likely to occur in individuals whose gender ideal or identity is high in femininity and empathy. Femininity and empathy thus form the framework of a self-schema that recognizes depressive symptoms as more "acceptable". Low femininity and empathy may cause an individual to resist the entry of these symptoms into his or her consciousness. Differences between participant genders in interpretation of the MDE case vignette as indicating illness, though not significant, may be explained by the fact that the ideal gender roles of Communion and Delicacy were significantly higher in females than males.

After passing the "filter" of illness recognition, symptoms were assessed in terms their somatic and psychological severity by variables other than gender identity or ideal gender role. Male participants attributed a male case with somatic symptoms to the psychological domain more often than they did a male case with emotional symptoms. Gender identity or ideal gender scores showed some correlation with the psychological severity rating but lost significance when participant gender was controlled for. Thus, gender role and identity seem to play a significant role in whether an individual interprets

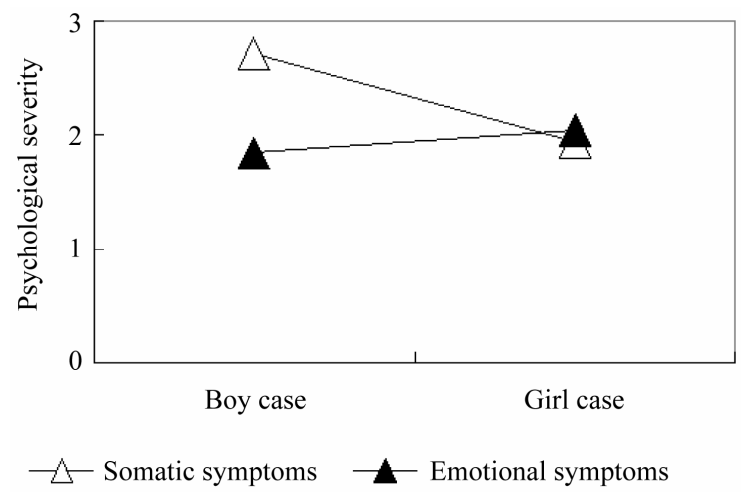

Figure 2. The psychological severity ratings of the male and female cases categorized by the predominant symptoms.

a case of MDE as illness, but it is the interaction of the case subject gender, participant gender, and predominant symptomatology that determines how people view the case subject as psychologically ill.

The implications of the present findings should be considered in future research. The marked difference in the prevalence of depression between the two genders was not entirely explained by our findings. However, these results could suggest that gender differences are partly explainable in terms of gender difference in the recognition of internal experiences (such as depressed mood, loss of interest, etc.) as signs of illness. If men feel that these experiences are normal for them, they may be less likely to respond affirmatively to questions regarding depressive symptoms. We may consider different cut-off of the MDE criteria or different set of diagnostic symptoms for MDE for men and women.

The present preliminary report suggests that reporting of depressive symptoms may be influenced by gender identity and that more care should be paid to the way in which these symptoms are investigated via questionnaire or interview.

\section{CONCLUSION}

Our conclusion should be regarded as tentative because of several study limitations. First, the relatively small number of participants and their young average age prohibit generalization of the study to populations with a broader age range. Second, a case presentation does not necessarily reflect the participants' internal experiences. However, direct enquiry into such internal experiences cannot address the possible "filtering" of internal experiences into the recognition of illness. Presentation of a case vignette, as used in this study, may be more advantageous in examining this issue.

\section{REFERENCES}

[1] Bebbington, P.E., Dunn, G., Jenking, R., Lewis, G., 
Brugha, T., Farrell, M. and Meltzer, H. (1998) The influence of age and sex on the prevalence of depressive conditions: Report from the national survey of psychiatric morbidity. Psychological Medicine, 28, 9-19.

http://dx.doi.org/10.1017/S0033291797006077

[2] Culbertson, F.M. (1997) Depression and gender. American Psychologist, 52, 25-31. http://dx.doi.org/10.1037/0003-066X.52.1.25

[3] Ernst, C. and Angst, J. (1992) The Zurich study: XII: Sex differences in depression: Evidence from longitudinal epidemiological data. European Archives of Psychiatry and Clinical Neuroscience, 241, 222-230. http://dx.doi.org/10.1007/BF02190257

[4] Kessler, R.C. and McLeod, J.D. (1984) Sex differences in vulnerability to undesirable events. American Sociological Review, 49, 621-631. http://dx.doi.org/10.2307/2095420

[5] Mirowsky, J. (1996) Age and the gender gap in depression. Journal health and Social Behavior, 37, 362-380. http://dx.doi.org/10.2307/2137263

[6] Murphy, J.M. (1986) Trends in depression and anxiety: Men and women. Acta Psychiatrica Scandinavia, 73, 113-127. http://dx.doi.org/10.1111/j.1600-0447.1986.tb10576.x

[7] Murphy, J.M., Sobol, A.M., Neff, R.K., Olivier, D.C. and Leighton, A.H. (1984) Stability of prevalence: Depression and anxiety disorders. Archives of General Psychiatry, 41, 990-997.

http://dx.doi.org/10.1001/archpsyc.1984.0179021007200 $\underline{9}$

[8] Tennant, C.C. (1985) Female vulnerability to depression. Psychological Medicine, 15, 733-738. http://dx.doi.org/10.1017/S0033291700004967

[9] Weissman, M.M., Leaf, P.J., Holzer, C.E., Myers, J.K. and Tischer, G.L. (1984) The epidemiology of depression: An update on sex differences in rates. Journal of Affective Disorders, 7, 179-188.

http://dx.doi.org/10.1016/0165-0327(84)90039-9

[10] Weissman, M.M., Bland, R., Joyce, P.R., Newman, S., Wells, J. E. and Wittchen, H.-U. (1993) Sex differences in rates of depression: Cross-national perspectives. Affective Disorders, 29, 77-84. http://dx.doi.org/10.1016/0165-0327(93)90025-F

[11] Anderson, J.C., Williams, S., McGee, R. and Silva, P.A. (1987) DSM-III disorders in preadolescent children. Archives of General Psychiatry, 44, 69-76. http://dx.doi.org/10.1001/archpsyc.1987.01800130081010

[12] Angold, A., Costello, E. J. and Worthman, C.M. (1998) Puberty and depression: The role of age, pubertal status, and pubertal timing. Psychological Medicine, 28, 51-61. http://dx.doi.org/10.1017/S003329179700593X

[13] Hyde, J.S., Mezulis, A.H. and Abramson, L.Y. (2008) The ABCs of depression: Integrating affective, biological, and cognitive models to explain the emergence of the gender difference in depression. Psychological Review, 115, 291-313. http://dx.doi.org/10.1037/0033-295X.115.2.291

[14] Meltzer, H., Gill, B., Petticrew, M. and Hinds, K. (1995)
The prevalence of psychic mobility among adults living in private households: OPCS Survey of Psychiatric Morbidity in Great Britain. Report 1. HMSO.

[15] Wilhelm, K. and Parker, G. (1993) Sex differences in depression genetic risk factors and coping strategies in a socially homogeneous group. Acta Psychiatrica Scandinavia, 88, 205-211. http://dx.doi.org/10.1111/j.1600-0447.1993.tb03440.x

[16] Cyranowski, J.M., Frank, E., Young, E. and Shear, K. (2000) Adolescent onset of the gender difference in lifetime rates of major depression. Archives of General Psychiatry, 57, 21-27. http://dx.doi.org/10.1001/archpsyc.57.1.21

[17] Piccinelli, M. and Wilkinson, G. (2000) Gender differences in depression: Critical review. British Journal of Psychiatry, 177, 486-492. http://dx.doi.org/10.1192/bjp.177.6.486

[18] Bebbington, P.E., Tennant, C. and Hurry, J. (1991) Adversity in groups with an increased risk of minor affective disorder. British Journal of Psychiatry, 158, 33-40. http://dx.doi.org/10.1192/bip.158.1.33

[19] Bebbington, P., Wilkins, S., Jones, P.B., Foester, A., Murray, R., Toone, B. and Lewis, S. (1993) Life events and psychosis: Initial results from the Camberwell Collaborative Psychosis Study. British Journal of Psychiatry, 162, 72-79. http://dx.doi.org/10.1192/bjp.162.1.72

[20] Brown, G.W. and Birley, J.L.T. (1968) Crises and life changes and the onset of schizophrenia. Journal of Health and Social Behaviour, 96, 203-214. http://dx.doi.org/10.2307/2948405

[21] Allen, D.M. and Tarriowski, K.J. (1989) Depressive characteristics of physically abused children. Journal of Abnormal Child Psychology, 17, 1-11. http://dx.doi.org/10.1007/BF00910766

[22] Turner, R.J. and Avison, W.R. (1989) Gender and depression: Assessing exposure and vulnerability to life events in a chronically strained population. Journal of Nervous and Mental Disease, 177, 443-455. http://dx.doi.org/10.1097/00005053-198908000-00001

[23] Nolen-Hoeksema, S., Parkder, L.E. and Larson, J. (1994) Ruminative coping with depressed mood following loss. Journal of Personality and Social Psychology, 67, 92-104. http://dx.doi.org/10.1037/0022-3514.67.1.92

[24] Turner, R.J. and Mario, F. (1994) Social support and social structure: A descriptive epidemiology. Journal Health and Social Behavior, 35, 193-212. http://dx.doi.org/10.2307/2137276

[25] McClain, L. and Abramson, L.Y. (1995) Self-schemas, stress, and depressed mood in college students. Cognitive Therapy and Research, 19, 419-432. http://dx.doi.org/10.1007/BF02230409

[26] Teasdale, J.D. and Barnard, P.J. (1996) Affect, cognitive and change: Remodeling depressive thought. Lawrence Erlbaum, Mahwah.

[27] Van Os, J. and Jones, P.B. (1999) Early risk factors and adult person-environment relationships in affective disorder. Psychological Medicine, 29, 1055-1067. http://dx.doi.org/10.1017/S0033291799001026 
[28] Markus, H. (1977) Self-schemata and processing information about the self. Journal of Personality and Social Psychology, 35, 63-78. http://dx.doi.org/10.1037/0022-3514.35.2.63

[29] Markus, H., Crane, M., Bernstein, S. and Siladi, M. (1982) Self-schemas and gender. Journal of Personality and Social Psychology, 42, 38-50. http://dx.doi.org/10.1037/0022-3514.42.1.38

[30] Laudrine, H. (1988) Depression and stereotypes of women: Preliminary empirical analyses of the genderrole hypothesis. Sex Roles, 19, 527-541. http://dx.doi.org/10.1007/BF00289722

[31] Yoder, C.Y., Shute, G.E. and Tyban, G.M. (1990) Community recognition of objective and subjective characteristics of depression. American Journal of Community Psychology, 18, 547-566. http://dx.doi.org/10.1007/BF00938059

[32] Stoppard, J. M., and Paisley, K. J. (1987) Masculinity, femininity, life stress, and depression. Sex Roles, 16, 489-496. http://dx.doi.org/10.1007/BF00292483

[33] Rice, J.K. and Rice, D.G. (1973) Implications of the women's liberation movement for psychotherapy. American Journal of Psychiatry, 130, 191-196.

[34] Simons, J.A. and Helms, J.E. (1976) Influence of counselors' marital status, sex, and age on college and noncolege women's councelor preferences. Journal of Counseling Psychology, 23, 380-386. http://dx.doi.org/10.1037/0022-0167.23.4.380

[35] Jones, E.E. and Zoppel, C.L. (1982) Impact of client and therapist gender on psychotherapy process and outcome.
Journal of Consulting and Clinical Psychology, 50, 259272. http://dx.doi.org/10.1037/0022-006X.50.2.259

[36] Zlotnick, C., Elkin, I. and Shea, M.T. (1998) Does the gender of a patient or the gender of a therapist affect the treatment of patients with major depression? Journal of Consulting and Clinical Psychology, 66, 655-659. http://dx.doi.org/10.1037/0022-006X.66.4.655

[37] Bridges, K.W. and Goldberg, D.P. (1985) Somatic presentation of DSM III psychiatric disorders in primary care. Journal of Psychiatric Research, 29, 563-569.

[38] Shafer, A.B. (2006) Meta-analysis of the factor structures of four depression questionnaires: Beck, CES-D, Hamilton, and Zung. Journal of Clinical Psychology, 62, 123 146. http://dx.doi.org/10.1002/jclp.20213

[39] American Psychiatric Association (1994) Diagnostic and statistical manual on mental disorders. 4th Edition, American Psychiatric Association, Washington DC.

[40] Radloff, L.S. (1977) The CES-D scale: A self-report Depression Scale for Research in the General Population. Applied Psychological Measurement, 39, 385-401. http://dx.doi.org/10.1177/014662167700100306

[41] Shima, S., Shikano, T., Kitamura, T.,and Asai, M. (1985) New self-rating scale for depression. Seishin Igaku (Clinical Psychiatry), 27, 717-723. (in Japanese)

[42] Ito, Y. (1986) Seiyakuwari-tokuseigo no imikouzou: Seiyakuwari sokuteishakudo "ISRS" sakusei no kokoromi [Factor structure of sex-role characteristics and its relation to agency and communion]. Japanese Journal of Educational Psychology, 34, 168-174. (in Japanese) 


\section{APPENDIX: CASE VIGNETTES OF MAJOR DEPRESSION}

\section{Case with Predominantly Emotional Symptoms}

For three months, Hiroshi/Yuuko has been busy at work as well in his/her private life. He/she has been feeling sad and has lost interest in everything; he/she feels as if people are trapped by convention so that everything seems boring.

$\mathrm{He} / \mathrm{she}$ feels miserable, and that he/she is worthless, unable to do anything, and is good for nothing. The idea that he/she raises concern among people whom he/she knows makes him/her feel very badly.

Friends who are worried about his/her condition invite him/her to have a drink. But whenever he/she attends a party, friends ask him/her one question after another, such as "What happened?" or "What's wrong?" Just when he/she is about to respond, they ask other questions so that he/she is unable to answer almost any questions at all. His/her boss criticises him/her, saying "Why don't you say anything?", "You are lazy", or "Stupid!"

Although it used to be a pleasure to go to parties, it is now a nuisance. Yet he/she is indecisive, thinking that declining the invitation may annoy his/her friends.

\section{Case with Predominantly Somatic Symptoms}

For three months, Hiroshi/Yuuko has been busy at work as well as in his/her private life. He/she has been exhausted every day for a month and has lacked backbone. He/she lacks patience for anything.

Even though he/she hasn't ever been ill for years, he/ she can't cheer himself/herself up. Because he/she has a poor appetite, he/she must force his/her mouth to swallow food.

After he/she gets home, he/she goes straight to bed. $\mathrm{He} / \mathrm{she}$ neglects to take baths or take off his/her clothes, but he/she does so reluctantly because his/her family scolds $\mathrm{him} / \mathrm{her}$. He/she has difficulty waking up, and he/she oversleeps. Lately he/she has often pretended to be sick and instead stays home until afternoon. Even though he/she sleeps for long time, he/she is too tired and exhausted to do anything.

Others ask him/her one question after another, such as "What happened?" or "What's wrong?" He/she can't answer their questions because they ask another question while he/she is still responding. Eventually they blame him/her, saying "Why don't you say anything?", "You are lazy", or "Stupid!" Some friends worry about him/ her and ask him/her to go out to dinner. However, this is a nuisance even though he/she used to be willing to go. 